\title{
ANDRÉ-JEAN ARNAUD E SUA CONTRIBUIÇÃO PARA A SOCIOLOGIA DO DIREITO
}

ANDRÉ-JEAN ARNAUD AND HIS CONTRIBUTION TO

THE BRAZILIAN SOCIOLOGY OF LAW

RESUMO: O presente artigo tem por objetivo determinar o grau de influência de André-Jean Arnaud no desenvolvimento da Sociologia do Direito no Brasil. Para tanto, metodologicamente, resta organizado nas seguintes etapas: publicações em Português e com edições brasileiras, seu fator de impacto enquanto pesquisador na produção científica do Brasil, projetos científicos desenvolvidos com pesquisadores e/ou instituições brasileiras, e, por fim, análise de questionário enviado a acadêmicos ligados à sociologia do Direito, no país.

Palavras-chave: André-Jean Arnaud. Brasil. Sociologia do Direito.
ABSTRACT: The paper seeks to determine the importance and influence of André-Jean Arnaud in the development of the Sociology of Law in Brazil. In order to accomplish this, it has been organized and divided as follows: Portuguese publications and Brazilian editions of his work, impact ratio of his research in the Brazilian scientific field, scientific projects developed with Brazilian scholars and/or institutions, and, finally, an analysis of a questionnaire sent to scholars connected to the Sociology of Law in Brazil.

\footnotetext{
${ }^{1}$ Coordenador do Mestrado em Direito e Sociedade do Unilasalle-Canoas. Diretor Executivo Acadêmico da Escola de Direito e Docente do Mestrado em Direito e Sociedade da Informação do Centro Universitário das Faculdades Metropolitanas Unidas (FMU). Pós-Doutor em Direito (University of Reading). Doutor em Direito (Unisinos) com estágio-sanduíche na Université Paris X-Nanterre. Pesquisador Produtividade em Pesquisa do CNPq (Nível 2).

${ }^{2}$ Professora do Mestrado em Direito e Sociedade do Unilasalle (Canoas-RS). Pós-Doutora em Direito (Instituto Internacional de Sociologia Jurídica de Oñati. Doutora em Direito (Unisinos), com estágio-sanduíche na University of Reading (Inglaterra).
} 


\section{INTRODUÇÃO}

Standing on the Shoulders of Giants. Para além de ser o quarto disco de uma das bandas de rock $^{3}$ de maior sucesso do anos 90 e dos anos 2000, o Oasis, a expressão representa uma metáfora. E é ela, a metáfora, que pretende explicar a influência de André-Jean Arnaud (AJA) no desenvolvimento da sociologia do Direito no Brasil.

Aliás, importante ressaltar. O presente artigo não tem como objetivo verificar o papel de AJA na evolução da sociologia do direito brasileira, porque tal movimento antecede até mesmo o nascimento do autor em comento (OLGIATI, 2011). Nesse sentido, ocupa-se de verificar de que maneira AJA contribuiu, a partir do momento em que se fez presente em terrae brasilis, com o desenvolvimento do que ali já existia. Uma sociologia do Direito incipiente.

Para tanto, como se verificará a seguir, o artigo resta estruturado em quatro etapas. (1) Na primeira, de caráter descritivo, procuram-se apontar as publicações de AJA em Português ${ }^{4}$ e por meio de edições brasileiras.

(2) Após, trata de apurar o impacto delas na produção científica brasileira, comparando, ainda, como isso ocorre em relação aos grandes nomes da sociologia (do Direito).

(3) Em um terceiro momento, apontam-se os projetos em que AJA se envolveu no Brasil.

(4) Por fim, a quarta etapa diz respeito à análise de questionário enviado aos pesquisadores da área sóciojurídica brasileira sobre o impacto de AJA em relação ao escopo do ensaio.

Retornando à metáfora e adiantando-se em relação ao conteúdo que se colocará a seguir, tal conotação possui um significado. Havia um tempo em que os anões andavam por sobre os ombros dos gigantes. Por que faziam isso? Para descobrir a verdade por meio de descobertas prévias. Na conhecida expressão de John de Salisbury: "se eu conseguisse ir além, seria por estar nos ombros de gigantes". Assim, seria possível enxergar adiante.

\footnotetext{
${ }^{3}$ Não é o problema do texto, mas para o leitor que deseje saber das conexões entre Direito \& Rock, veja-se SCHWARTZ (2014).

${ }^{4}$ Muito embora exista um acordo ortográfico entre os países de língua portuguesa, o fato é que o português "brasileiro" guarda particularidades com relação à língua de Camões.
} 
Um novo futuro. Para que seja claro. Na metáfora, para o artigo, AJA era o gigante, e a sociologia do direito brasileira conseguiu enxergar o futuro porque, entre outros motivos, pôde contar com seus ombros.

\section{AS PUBLICAÇÕES DE AJA NO BRASIL}

Não é rotineiro que autores estrangeiros, ainda mais de sociologia do Direito, tenham suas obras traduzidas para o Português falado no Brasil, um "filho rebelde" daquele praticado em Portugal. Na mesma linha de raciocínio, muito embora o mercado editorial jurídico brasileiro seja de monta, tendo em vista que há mais de 1149 cursos de Direito (DIREITO O. D., 2016) no país e que a disciplina de sociologia do Direito é obrigatória em todos eles (EDUCAÇÃO, 2016), também não se pode dizer que exista uma aposta forte em tal segmento (autores estrangeiros de sociologia do Direito traduzidos para o português "brasileiro").

Um cotejo com outros autores revela tal dificuldade. Retirando-se aqueles que se podem denominar de autores clássicos da sociologia (Marx, Weber, Durkheim) e outros sociólogos que se ocupam, também, do Direito (Luhmann, Bourdieu, Foucault, somente para exemplificar), é oportuno focar em autores contemporâneos a AJA e que, para o bem ou para o mal, são entendidos como sociólogos do Direito.

A verificação não pretende esgotar a quantidade de autores. Para isso, utiliza os nomes apontados por Olgiatti (2011) e por Podgórecki (1989) como essenciais para a criação do Research Committee on Sociology of Law (RCSL) da International Sociological Association (ISA). Faz-se essa delimitação porque é o RCSL um dos grandes atores da afirmação da sociologia do Direito enquanto disciplina autônoma (Guibentif, 2014), e, também, porque AJA a ele se dedicou com especial ênfase. A lista dos presidentes do RCSL e de quem auxiliou sua construção está disponível online (LAW R. C., 2016) e representa o primeiro recorte.

Outro marco, o segundo recorte para a pesquisa proposta, é o Instituto Internacional de Sociologia Jurídica de Oñati - IISL - (LAW I. I., 2016). AJA foi seu primeiro Diretor e o Instituto, de fato, é a concretude dos ideais do RCSL (PODGORECKI, 1989). Seus 
presidentes podem ser considerados, portanto, contemporâneos de Arnaud e, desse modo, a comparação passa a ser consistente.

A análise restará focada, por ser a única fonte confiável para se fazer tal comparação, na publicação de livros. Veja-se: apenas recentemente, dos anos 2000 em diante e, no Direito, mais fortemente a partir do ano de 2008, é que a publicação de artigos científicos tem sido estimulada pela CAPES (Coordenação de Aperfeiçoamento de Pessoal de Nível Superior), a agência do governo brasileiro que possui a tarefa de autorizar e renovar autorização de cursos de Mestrado e de Doutorado. Ela faz isso por meio do Sistema Qualis, que categoriza, por meio de alguns critérios, as revistas, e pelos Documentos de cada área do saber que, por seu turno, valora tais publicações.

Nesse sentido, o livro mais bem avaliado vale 200 pontos; o artigo, de seu lado, 100 pontos. Logo, bastam dois artigos em revista Qualis A1 para se obter a mesma pontuação de um livro. Mas essa é uma abordagem recente. A realidade, todavia, é que a produção científica jurídica brasileira, mesmo com a forte indução da CAPES, ainda se concentra, de um modo muito forte, em livros (CAPES Á. D., 2016) e é isso que traz confiabilidade ao levantamento a seguir.

\begin{tabular}{|l|l|l|}
\hline AUTOR & $\begin{array}{l}\text { LIVROS EM } \\
\text { PORTUGUÊS DO BRASIL }\end{array}$ & TíTULO \\
\hline André-Jean Arnaud & 13 & $\begin{array}{l}\text { O Direito Traído pela Filosofia } \\
\text { Governar sem Fronteiras - Entre Globalização e Pós-Globalização } \\
\text { Introdução à Análise Sociológica dos Sistemas Jurídicos } \\
\text { O Direito entre Modernidade e Globalização } \\
\text { Dicionário Enciclopédico de Teoria e Sociologia do Direito } \\
\text { Dicionário da Globalização : Direito - Ciência Política } \\
\text { Anuário Direito e Globalização - A Soberania. } \\
\text { Direito e Globalização II. Fatos e Teorias. } \\
\text { Anuário 2000 GEDIM. } \\
\text { Anuário 2001 GEDIM. } \\
\text { Anuário 2002 GEDIM. } \\
\text { Anuário 2003 GEDIM. } \\
\text { Niklas Luhmann: do Sistema social à sociologia jurídica }\end{array}$ \\
& & $\begin{array}{l}\text { Contar a Lei. As Fontes do Imaginário Jurídico. } \\
\text { O Tempo do Direito. }\end{array}$ \\
\hline François Ost & 2 & Direito, Sistema e Policontexturalidade \\
\hline Gunther Teubner & 1 & Sociologia do Direito \\
\hline Renato Treves & 1 & \\
\hline
\end{tabular}

O quadro é revelador e demonstra o tamanho do impacto da produção científica de AJA e de sua influência na sociologia do direito brasileira. Não há nenhum contemporâneo 
seu com sequer um número parecido de publicações de livros em Português do Brasil.

Aduza-se que os seguintes autores que, pelo critério estabelecido, são contemporâneos a AJA, obtiveram o índice de nenhum livro publicado em Português (do Brasil): Adam Czarnota, Adam Podgórecki, Angela Melville, Anne Boigeol, Carlos Lista, Jacek Kurczewski, Jan Glastra Van Loon, Jean Carbonnier, Jean Van Houtte, Johannes Feest, Joxerramon Bengoetxea, Lawrence Friedman, Manuel Calvo-Garcia, Masaji Chiba, Mavis MacLean, Paavo Uusitalo, Per Stjernquist, Roberto Bergallo, Rogelio Perez Perdomo, Sandra Burman, Sol Picciotto, Vincenzo Ferrari, Vittorio Olgiatti, William Evans, William Felstiner e Wolkmar Gessner.

Uma ausência pode ser notada no quadro. Boaventura de Sousa Santos. Ele possui, à evidência, muitas obras em Português e é, certamente, um dos autores de maior repercussão na academia brasileira. Ocorre que o fato de o Português ser sua língua materna facilita a leitura das obras diretamente no original, isto é, por meio de edições portuguesas. Logo, a partir do recorte do presente artigo, inegável que AJA é o sociólogo do Direito com maior número de publicações em editoras brasileiras e em Português "brasileiro". Mas quantidade não é sinônimo de qualidade. A afirmação é verdadeira?

\section{O FATOR DE IMPACTO DAS PUBLICAÇÕES DE ANDRÉ-JEAN ARNAUD NO BRASIL}

O estudo do fator de impacto das publicações científicas brasileiras revela-se incipiente. Com efeito, na área do Direito, o único sistema conhecido é o Indexa Conpedi. O Conpedi é o Conselho Nacional de Pós-Graduação em Direito, uma entidade privada que tem por objetivo auxiliar e alavancar os programas de pós-graduação em Direito no país.

Nesse sentido, o Conpedi organiza, semestralmente, congressos que são o ponto de encontro do estado da arte no Direito brasileiro. Anais são produzidos com base nos papers apresentados em seus vários Grupos de Trabalho. Sua publicação é dada de maneira digital. Eles são uma das fontes do Indexa (DIREITO C. N.-G., 2016), ferramenta que busca, de maneira automática, indicadores de citações em documentos eletrônicos. A outra é base de dados proveniente do Portal de Periódicos da CAPES (CAPES, 2016).

As tabelas que seguem contemplam algumas categorias. A primeira coluna diz respeito à posição do autor no ranking geral do Indexa; a segunda é a descrição do seu 
nome; a terceira, por seu turno, diz respeito ao número de citações; a quarta, aduzindo, refere-se à quantidade de documentos individuais em que se encontram as citações; a quinta, de outra banda, é o índice $\mathrm{H}$ do pesquisador.

Na primeira tabela, foram inseridos os autores considerados como sociólogos, sem qualquer divisão específica para a sociologia do Direito. Nessa linha de raciocínio, AJA é o 287으 autor mais citado no país, mas figura entre os 13 primeiros quando se analisa sua obra somente sob o prisma de pesquisadores ligados à sociologia. Um belo resultado.

\begin{tabular}{|l|l|l|l|l|}
\hline INDEXA & AUTOR & CITAÇÕES & $\begin{array}{l}\text { DOCUMENTOS } \\
\text { INDIVIDUAIS }\end{array}$ & ÍNDICE h \\
\hline 10 & Boaventura de Souza Santos & 1387 & 201 & 13 \\
\hline 21 & Zygmunt Bauman & 761 & 119 & 8 \\
\hline 26 & Niklas Luhmann & 715 & 117 & 9 \\
\hline 34 & Ulrich Beck & 638 & 106 & 8 \\
\hline 40 & Michel Foucault & 568 & 102 & 9 \\
\hline 54 & Anthony Giddens & 476 & 85 & 8 \\
\hline 66 & Pierre Bourdieu & 388 & 64 & 8 \\
\hline 72 & Manuel Castells & 357 & 91 & 7 \\
\hline 76 & François Ost & 340 & 89 & 5 \\
\hline 90 & Karl Marx & 320 & 78 & 8 \\
\hline 197 & Michel Villey & 162 & 46 & 5 \\
\hline 249 & Alain Touraine & 138 & 40 & 6 \\
\hline 281 & André-Jean Arnaud & 124 & 42 & 4 \\
\hline 326 & Jaques Derrida & 111 & 25 & 5 \\
\hline 427 & Gunther Teubner & 79 & 27 & 4 \\
\hline
\end{tabular}

Quando o recorte repousa única e exclusivamente entre os sociólogos do Direito, AJA passa a ser o quarto mais citado no país conforme se infere da tabela abaixo.

\begin{tabular}{|l|l|l|l|l|}
\hline INDEXA & AUTOR & CITAÇÕES & $\begin{array}{l}\text { DOCUMENTOS } \\
\text { INDIVIDUAIS }\end{array}$ & ÍNDICE H \\
\hline 10 & Boaventura de Souza Santos & 1387 & 201 & 13 \\
\hline 76 & François Ost & 340 & 89 & 5 \\
\hline 197 & Michel Villey & 162 & 46 & 5 \\
\hline 281 & André-Jean Arnaud & 124 & 42 & 4 \\
\hline 427 & Gunther Teubner & 79 & 27 & 4 \\
\hline
\end{tabular}

O décimo-terceiro sociólogo de maior impacto na academia brasileira e o quarto sociólogo do Direito de maior influência no Brasil. Esses são os números de AJA. Quantidade e qualidade. Mas como ele chegou a tal resultado? Em que projetos eles se envolveu no Brasil? 


\section{OS PROJETOS DE AJA NO BRASIL}

Para que conseguisse chegar ao nível de influência registrado anteriormente, AndréJean Arnaud dedicou boa parte de seu tempo a projetos ligados, de uma maneira ou de outra, ao Brasil. Nesse sentido, relembra Wanda Capeller (1991) que o pensamento de AJA, transgressor por natureza, restava apto a provocar mudanças no establishment da academia brasileira.

Os projetos de AJA no Brasil podem ser vistos sob o prisma de uma tríade. A partir dela se denota a amplitude dos eixos colaborativos que o autor estabeleceu entre o Brasil e o restante do mundo, envolvendo instituições e pesquisadores em esforços conjuntos na área da Sociologia do Direito.

Como o líder da Cátedra Unesco em Direitos Humanos, Violência, Políticas Públicas e Governança, sediada e estabelecida no ano de 2005 na Universidade Externado de Colômbia, AJA reuniu várias universidades. Do exterior, para além da já citada instituição colombiana, participam - porque ainda ativa - a Universidade Carlos III (Madrid), a Universidade de Camerino (Itália) e a Universidade de Paris X-Nanterre; do Brasil, compõem a Cátedra a Pontifícia Universidade Católica do Rio de Janeiro, a Universidade Federal da Paraíba e a Universidade do Vale do Rio dos Sinos.

Como se percebe com clarividência, tal projeto conectou a academia brasileira à europeia e à latino-americana em torno de um tema bastante caro à Sociologia do Direito. Os objetivos (ARNAUD, 2016) do projeto são bastante elucidativos:

(a) promover e integrar um sistema de pesquisa, treinamento, informação e documentação nos campos dos direitos humanos, da violência, das políticas públicas e da governança, contribuindo, assim, para uma cultura de direitos humanos e de paz;

(b) facilitar a colaboração entre acadêmicos e professores reconhecidos e de alto nível de universidades e de outras instituições na Colômbia e em outras localidades da América Latina e do Caribe, bem como em outras regiões do mundo.

O outro grande projeto de AJA no Brasil consistiu no Programa Interdisciplinar GEDIM (Globalização Econômica e Direitos no Mercosul). AJA foi seu líder, e o Líder da Antena no Rio de Janeiro, sede efetiva do projeto, foi Gabriel de Assis Almeida, da Escola de Ciências Jurídicas da Universidade do Rio de Janeiro. 
O projeto GEDIM restava conectado ao programa MOST Unesco (The Management of Social Transformations). Este objetivava avaliar o impacto da pesquisa nas tomadas de decisões, procurando determinar se os tomadores de decisão utilizam as pesquisas para implementar, reorientar ou modificar as políticas públicas; aquele, por seu turno, organizava-se a partir de quatro linhas de pesquisa (GEDIM, 2016):

(a) reestruturação do Direito Empresarial em Contexto Globalizado. Dr. José Gabriel de Assis Almeida;

(b) a Reestruturação das Instituições de Controle em Face da Globalização e do Comércio Ilegal. Dr. Cesar Caldeira e Emilio Dellasoppa;

(c) preliminar para uma Reestruturação da Justiça: uma carta judiciária. Dra. Maria Teresa Carcomo Lobo e Jacques Commaille;

(d) Privatização, Regulação dos Serviços Públicos e Direitos de Cidadania.

O GEDIM constitui um dos projetos mais frutíferos de AJA no Brasil. Dele surgiram os Anuários do GEDIM e os Anuários da Globalização, ambos mencionados no item 1 do presente artigo. Também foi um grande pólo de articulação de conhecimento, inclusive por conectar regiões distintas do país, de novo, ao pensamento estrangeiro.

Não se esqueça, ainda, de que AJA atuou, nos anos de 2002 a 2003, como professor do Mestrado e do Doutorado em Direito da Universidade do Vale do Rio dos Sinos, local em que orientou teses de doutorado e dissertações de mestrado, participando, ainda, de bancas de arguição em ambos os níveis. Essa atividade também alavancou sua capilaridade entre a comunidade sóciojurídica brasileira.

Desse modo, constata-se que há várias razões para a influência de AJA na Sociologia do Direito no Brasil. Contudo, para além do exemplo de empreendedorismo e de academicismo, um outro aspecto se evidenciou deveras importante para que houvesse tal consolidação: o caráter. A pesquisa, a seguir, procura demonstrar como Arnaud era percebido por seus pares brasileiros, o último dado para explicar sua relevância no contexto do desenvolvimento da sociologia do Direito brasileira. 


\title{
5 ANDRÉ-JEAN ARNAUD POR SEUS PARES BRASILEIROS
}

Já se apontou anteriormente a influência de AJA na sociologia do Direito brasileira por meio de critérios quantitativos e qualitativos, ambos de caráter objetivo. Há, porém, uma outra percepção, bastante importante: a subjetiva. Os passos desse gigante foram sentidos no Brasil não somente por sua produção intelectual e por sua atuação profissional. Seus ombros eram muito mais largos. Nesse sentido, Orlando Villas Bôas Filho $(2016, p$. 124) sumariza o pensamento da academia brasileira com relação ao autor:

\begin{abstract}
A versatilidade e a desenvoltura com que transitava pelos âmbitos do direito, da sociologia, da filosofia e da história desorientavam seus leitores, sobretudo os mais ávidos por enquadrar seu pensamento em algum domínio mais definido. Era, nesse sentido, um teórico inclassificável e perturbador. A erudição que the franqueava a passagem de um domínio do saber a outro se aliava à sua aversão às ortodoxias e aos paroquialismos acadêmicos. Sua capacidade de, com elegância, subverter as certezas que norteiam os olhares acomodados e as esquematizações dogmáticas que acalentam o sono dos juristas arraigados a representações defasadas e simplificadoras da regulação jurídica na sociedade hodierna deve inspirar todos aqueles que pretendam efetivamente compreendê-la.
\end{abstract}

No Prefácio da obra “O Direito Traído pela Filosofia”, Wanda Capeller (1991, p. 7), classifica o "olhar transgressor" de AJA como uma de suas características e uma das grandes qualidades do pensamento elaborado pelo autor, ressaltando, ainda, sua correlação com o momento do Brasil da retomada da democracia.

Para comprovar o que ora se afirma procedeu-se a um questionário com doze perguntas e uma questão aberta. Ele foi enviado para vinte e oito pessoas. Acadêmicos de quilate e que tiveram contato com AJA durante seus projetos no Brasil (item 3 do presente artigo). Algumas dessas pessoas foram seus alunos ou seus orientandos. Houve dez respostas. Em uma delas, o respondente optou por deixar apenas um testemunho.

Da referida pesquisa emergem alguns dados que reforçam o propósito do presente artigo. A saber:

(a) A faixa etária é composta de $77, \%$ de acadêmicos com mais de quarenta e nove anos e o restante se encontra entre trinta até quarenta e nove anos.

(b) Os entrevistados conheceram AJA, em sua maioria, na década de 90 do século passado $(55,55 \%)$ e o restante se divide, igualmente, entre aqueles que travaram contato pessoal com o autor ou na década de oitenta do século XX ou no início do século XXI. 
(c) A primeira experiência com AJA se deu na forma de leitor de suas obras (33,33\% em língua estrangeira e 22,22\% em Português). Os demais foram alunos do autor no Brasil $(33,33 \%)$.

(d) Dos entrevistados, 55,55\% tiveram o primeiro contato durante seu curso de doutoramento ou após sua conclusão, e, atualmente, 100\% deles são doutores.

Aqui é possível perceber um padrão bastante evidente. Os entrevistados fizeram seus cursos de doutorado na época do renascimento da democracia brasileira. É o período imediatamente posterior à promulgação da Constituição Federal de 1988. Nesse lapso temporal, é que a influência da AJA se tornou importante, por meio da leitura de suas obras, para todos, que, hoje, são pesquisadores assentados e experientes.

Nessa esteira, os respondentes $(44,44 \%)$ elencam como a mais importante obra de AJA, em Português do Brasil, o livro "O Direito Traído pela Filosofia", editado no ano de 1991 pela Sergio Fabris Editora - Porto Alegre - (ARNAUD, 1991). Não por acaso, o livro se dedica, entre outros, ao fato de que os juristas devem lutar contra a dogmática para que voltem à realidade do Direito, operado em sua rotina cotidiana (história e tempo), reforçando a tese outrora exposta de que seu pensamento se coadunava perfeitamente com o espírito da redemocratização brasileira.

O segundo livro mais importante, com 33,33\% das respostas, é "A Introdução à Análise Sociológica dos Sistemas Jurídicos", editado pela Renovar, do Rio de Janeiro, no ano de 2000 (ARNAUD; DULCE). Em coautoria com Fariñas Dulce Trata-se de obra em que se sistematiza o conhecimento sobre a Sociologia do Direito e que é, até, hoje, uma das obras citadas em bibliografias básicas de cursos da disciplina retrorreferida nas Faculdades de Direito do país.

A terceira obra citada pelos respondentes é o "Dicionário Enciclopédico de Teoria e de Sociologia do Direito" (ARNAUD, 1999) consiste num marco no desenvolvimento da Sociologia do Direito brasileira, pois envolveu cerca de vinte acadêmicos brasileiros em sua feitura e, também, porque deixou explicitada a autonomia - nem sempre muito clara - da sociologia do Direito frente a Teoria do Direito.

De outro lado, o projeto que se considerou de maior impacto foi o já mencionado GEDIM (Programa Interdisciplinar Globalização Econômica e Direitos no Mercosul), com 
44,44\% das respostas, seguido do projeto Cátedra Unesco Direitos Humanos e Violência, Governo e Governança, que obteve o mesmo resultado do Dicionário de Globalização, cada um com 22,22\%. Uma resposta mencionou a atuação de AJA como orientador de mestrado, doutorado ou de pós-doutorado.

Na mesma linha, porém, referindo-se a projetos no exterior, o de maior importância para os acadêmicos brasileiros, sem dúvida, é o Instituto Internacional de Sociologia Jurídica de Oñati, com 77,77\% das respostas. Como já dito, AJA foi seu primeiro Diretor e sempre o divulgou quando esteve no Brasil. O resultado de seu trabalho pode ser visto em vários números, como, por exemplo, o fato de onze estudantes brasileiros terem cursado, até o presente momento, o Mestrado em Sociologia Jurídica do Instituto.

Não é de estranhar, assim, o fato de que $100 \%$ dos acadêmicos brasileiros que responderam ao questionário, definem AJA como influente ou altamente influente no desenvolvimento da Sociologia do Direito no Brasil, escorado em suas características pessoais, apontadas pelos respondentes, tais como: rigorismo científico, inovação e empreendedorismo.

Esse, talvez, possa ser o maior legado de AJA para a Sociologia do Direito no Brasil. Uma influência dada a partir do exemplo científico e por meio da atuação ativa em seus projetos. Mas esse legado não parou aí. Arnaud também foi um modelo pessoal para tais pessoas conforme é possível notar a partir das falas livres encontradas na última parte do questionário:

Personalidade marcante, grande intelectual, sensível aos temas de uma sociologia jurídica na america Latina, capacidade crítica e inovadora

Não só o gesto de compartilhar e querer me ajudar com o material que dispunha naquele momento, mas também seu empenho em manter meu interesse vivo, foram atitudes determinantes para minha futura escolha em seguir o magistério superior e a área de teoria do direito. Não há palavras que possam descrever o quanto eu sou grato ao Professor Arnaud.

O AJA abriu as portas da Europa para mim. Por intermédio deles conheci todos os professores relevantes à época no meu corte de pesquisa. Foi a partir do AJA que travei contato com Teubner, com Ost, com o IISL, com Febbrajo, com Clam, somente para citar alguns. Minha tese não teria sido a mesma sem o AJA.

AJA foi uma das pessoas mais inteligentes, mais preparadas, mais intelectualmente brilhantes e mais generosas que conheci. Foi, para mim, uma honra e uma alegria ter podido trabalhar com ele e ter podido desfrutar da sua amizade.

André-Jean Arnaud teve uma importância fundamental na Academia Brasileira, em diferentes momentos, desde a influência na Sociologia do Direito e na teria 
jurídica crítica, época em que conheci sua obra e que pautou minhas respostas, mas também posterior e continuadamente, na área da Globalização e da Governança, sempre protagonizando uma liderança na América Latina e no Brasil, seja pela produção de obras muitos importantes ou da criação de cátedras, programas e projetos inovadores, o que constituía uma marca de seu espírito também.

Frente a tais depoimentos e aos dados apresentados, pode-se auferir a magnitude de AJA para a Sociologia do Direito no Brasil. Seu passamento enlutou toda a comunidade sóciojurídica brasileira, deixando órfãos aqueles que, com ele, travaram contato e, também, infelizmente, os que não tiveram a oportunidade de conhecê-lo. Mas suas obras, sua influência, e, principalmente, seu exemplo, restam perenes.

\section{CONSIDERAÇÕES FINAIS}

Em sede de considerações finais, após esse breve passeio sobre a influência de AJA na Sociologia do Direito do Brasil, vale destacar o que se considera como pontos fundamentais para a penetração do autor em solo brasileiro:

(a) Sua teoria, ligada a uma pluralidade de atores e de fontes jurídicas, especialmente quando dedicada aos estudos da globalização e do Direito (Filho, 2016), é, tanto quanto as teses de Boaventura de Sousa Santos, consectária dos movimentos democráticos que o Brasil viveu antes e depois da Constituição de 1988. Daí a sua alta utilização pelos acadêmicos nacionais, preocupados com a construção de um Estado Democrático de Direito.

(b) Sua dedicação ao Brasil, espelhada em seus projetos e em suas publicações, proporcionou aos acadêmicos brasileiros uma vivência pessoal com o autor que fugiu à regra de seus contemporâneos estrangeiros e proporcionou, assim, um diálogo frutífero para ambos os lados.

(c) Seu caráter de "construtor de pontes", demonstrado pela pesquisa empírica realizada no presente artigo, significou um diferencial. Por seu intermédio, vários intercâmbios foram construídos, e muitos pesquisadores tiveram acesso a um amplo e variado espectro de universidades, de pesquisadores e de projetos.

(d) Publicar em Português e, em especial, o falado no Brasil, também contribuiu fortemente para o impacto de AJA no país. O fato de tais publicações serem viabilizadas por editoras 
brasileiras tornou o preço mais barato e, logo, o acesso ao conhecimento, mais plausível.

Nessa esteira, a partir dos itens retrorreferidos, verifica-se que a metáfora utilizada no presente texto está de acordo com o sentido que John de Salisbury, em 1159, em seu Metalogicon, forneceu à expressão. É fato que as gerações posteriores a AJA na Sociologia do Direito do Brasil conseguiram enxergar além das anteriores. Mas não fizeram isso porque possuíam uma observação mais ampla ou mais acurada. Também não se deve a uma maior estatura (acadêmica) de um ou de outro. A razão é que, por sob os ombros de Arnaud, conseguiu-se vislumbrar algo que outrora era turvo, distante.

Por fim, em função de tudo o que o presente artigo argumentou, e parafraseando uma das músicas de maior sucesso da Legião Urbana, banda de rock altamente influente no Brasil no período da redemocratização, pode-se dizer que a Sociologia do Direito no Brasil foi altamente influenciada pelo autor em comento. De fato, após AJA, e sem medo de errar, nosso futuro não é mais como era antigamente!

\section{REFERÊNCIAS}

ARNAUD, A.-J. O Direito Traído pela Filosofia. Porto Alegre: SAFE, 1991.

ARNAUD, A.-J. Dicionário Enciclopédico de Teoria e de Sociologia do Direito. Rio de Janeiro: Renovar, 1999.

ARNAUD, A.-J. Cátedra Unesco em Direitos Humanos, Violência, Políticas Públicas e Governança. Fonte: Cátedra Unesco em Direitos Humanos, Violência, Políticas Públicas e Governança. 21 de Junho de 2016. Disponível em: <http://portal.unesco.org/education/en/ev.phpURL_ID=43342\&URL_DO=DO_TOPIC\&URL_SECTION=201.html>.

ARNAUD, A.-J.; DULCE, M. J. Introdução à Análise Sociológica dos Sistemas Jurídicos. Rio de Janeiro: Renovar, 2000.

CAPELLER, W. André-Jean Arnaud: uma obra de transgressão. In: ARNAUD, A.-J. O Direito Traído pela Filosofia. Porto Alegre: SAFE, 1991. p. 7-21.

CAPES. Portal Periódicos da CAPES. Fonte: Portal Periódicos da CAPES. 21 de Junho de 2016. Disponível em: <www.periodicos.capes.gov.br>.

CAPES, Á. D. CAPES. 21 de Junho de 2016Fonte: CAPES. Disponível em: <https://www.capes.gov.br/images/stories/download/avaliacaotrienal/Docs_de_area/Direit o_doc_area_e_comissão_16out.pdf>.

DIREITO, C. N.-G. Indexa Conpedi. Fonte: Indexa. 19 de Junho de 2016. Disponível em: <http://150.162.138.7/documents;jsessionid=F559E310CACB5D979ABB0A63F23FF4D3?pag $\mathrm{e}=138 \&$ size $=20>$. 
DIREITO, O. D. Observatório do Ensino do Direito GV-SP. Fonte: Observatório do Ensino do Direito GV-SP. 21 de Junho de 2016. Disponível em: <http://direitosp.fgv.br/observatorioensino-direito>.

EDUCAÇÃO, C. N. Portal do MEC. Fonte: Portal do MEC. 21 de Junho de 2016. Disponível em: <http://portal.mec.gov.br/cne/arquivos/pdf/rces09_04.pdf>.

FILHO, O. V. O Impacto da Governança sobre a Regulação Jurídica Contemporânea : uma abordagem a partir de André-Jean Arnaud. REDES - Revista Eletrônica Direito e Sociedade, 4, 1, p. 123-144, mai. 2016. DOI: 10.18316/2318-8081.16.16. Disponível em: <http://dx.doi.org/10.18316/2318-8081.16.16 >.

GEDIM. GEDIM. Fonte: GEDIM. 21 de Junho de 2016 . Disponível em: <http://www.unesco.org/most/globalization/Networks-projects.htm>

GUIBENTIF, P. The Force of Science and the Force of Organizations. Some Exploratory Thoughts Applied to the Example of the Oñati International Institute for the Sociology of Law . Sortuz. Oñati Journal of Emergent Socio-legal Studies, 6, 1, 67-81, 2014.

LAW, I. I. IISJ. Fonte: IISJ. 21 de Junho de 2016. Disponível em: <http://www.iisj.net/iisj/de/presentacion.asp?cod=5154\&nombre=5154\&prt=1>.

LAW, R. C. RCSL Tribute. Fonte: RCSL. 21 de Junho de 2016. Disponível em: <http://rcsl.iscte.pt/rcsl_intro_Tribute.htm>.

OLGIATI, V. The Institutional Internationalisation of Sociology of Law. Revista da ABRASD, 1, 9-36, 2011.

PODGORECKI, A. The Changing Philosophy of the Research Committee of Sociology of Law (ISA). Oñati, Gipuzkoa, Espanha: IISJ, 1989. p. 12-29.

SCHWARTZ, G. Direito \& Rock: expectativas normativas da Constituição de 1988 e do Junho de 2013. Porto Alegre: Livraria do Advogado, 2014. 